\title{
PARENTAL RESPONSIBILITIES TOWARDS TECHNOLOGY INTEGRATION FOR OUT-OF-SCHOOL TIME LEARNING
}

\author{
Dr. Thadei A. Kiwango \\ Lecturer, \\ Department of Informatics, \\ Institute of Accountancy Arusha, \\ P. O. Box 2798 Arusha, \\ Tanzania.
}

Article DOI: https://doi.org/10.36713/epra3591

\begin{abstract}
This paper is an assessment of parental responsibilities in relation to supporting integration of technology in the context of out-of-school time (OST) learning. The assessment involved 78 parents from Arusha, Dar es Salaam and Mwanza regions in Tanzania. The aim was to discover the practices among parents in supporting their children to use educational technology in the home context. Criterion sampling applied and 11 best schools were picked from 11 divisions based on the 2015 NECTA Primary School Leaving Examination (PSLE) results. It is shown that parents have the potential to support the use of educational technology among children through procurement of educational technology, guiding material on the use of educational technology and giving instructions on the use of educational technology. Parents can also guide pupils on best to write summaries of key concepts, and also give questions on learned concepts. Moreover, parents are also potential for identifying useful programmes for use with educational technology thereby making children use technology for educational pursuits and avoid technology abuse and thus enhance their academic performance. The findings suggest the need for the schools to cooperate with parents and communities with a view to fostering the parental roles in the utilization of educational technology for OST learning. Further studies on how to improve the parental support towards the educational technology use by OST learners is inevitable in this digital world.
\end{abstract}

\section{INTRODUCTION}

The Indianapolis Afterschool Coalition (2002) views out-of-school time (OST) as comprising a variety of instructional activities before and after school, on weekends and during the vacations. This is a form of learning that complements the conventional classroom learning, and therefore, it can be improved through integration of educational technology. The efforts for the integration of educational technology in the educational system has been taken at global, regional and national settings. The World Summit on the Information Society (WSIS) (2003) requires nations to ensure that information and communication technology (ICT) is integrated into their educational systems. In response to this call, the African Ministerial Forum on ICT Integration in Education and Training instructed all African nations to adopt policies which favour integration of educational technology into their education systems (Association for the Development of Education in Africa, 2013). Technology integration for African countries in particular is important as it helps them to avoid maginalization in the context of the everincreasing global competitive environment (Kiwango, 2004).

ICT is accommodated in the Tanzania Vision 2025 as key towards social and economic advancement and poverty reduction; and this demands the use of ICT in all sectors of the economy and national life. In education and training, adequate investment in ICT is imperative if the quality of education is to be improved from the lowest levels. In the same veins, the Tanzanian National ICT Policy of 2016 aims at 
improving human capital to enhance its capacity to ICT and consequently create a knowledge-based society. To this end, the Government of Tanzania encourages sustainable learning and use of ICT; which also entails effective application of ICT in the teaching and learning process. The Policy also demands that the Government enhance participation and understanding of its population on the usefulness of ICT to realize the goal of becoming a knowledge-based society.

Although concerted efforts have been made to integrate technology in education in various countries, the OST environment does not seem to be sufficiently considered. Consequently, even when technology procured, OST learners have been found to continuously abuse such an important window. For example, the UNICEF (2011) found that only $13.5 \%$ of learners used ICT to do their school assignments while $30 \%$ of learners spent most of their time chatting on social networks and $16 \%$ of them watched nonacademic television programmes and movies. Moreover, hanging out with friends occupied $12 \%$ of the learners and 4\% played computer games.

Similar findings reverberate in Terzian, Giesen, and Mbwana (2009) who found that access to learning technology does not necessarily translate to enhanced academic achievements; instead, access to educational technology needs to be backed up by pertinent strategies that can inspire learners perceive technology positively and consequently put to use. Terzian, et al. (2009) join Davis (1986) and Rogers (2003) and testify that technology adoption is equally cherished by psychological orientation and persuasion. In the same veins, Kiwango (2006) unveiled that Tanzania's efforts towards effective exploitation and nurturing of the ICT industry are significantly sanctioned by inadequate availability and applications of contextual frameworks for ICT integration particularly in OST settings. This research paper is an attempt to determining the responsibilities of parents in supporting pupils at home to efficiently use technology to enhance learning.

Parents are thus taken as important stakeholders in the education of their children, since they are also part and parcel of the community in which they live. This fact also aligns with the Epstein's Theory as it acknowledges parents as among the most important actors in the welfare and lives of children (Zedan, 2011). In the views of Epstein (2002), who is also the founder of this theory, involvement of parents in nurturing and guiding children to a great extent affects achievements in learning as it can be evident in six areas. The first evidence pertains to parenting; whereby parents are involved in all activities which are intended to raise children who are committed to learning activities. This is followed by communication as the second proof as parents are expected to supply teachers with information regarding their children's educational practices.

Volunteering constitutes the third area of Epstein view as parents tend to volunteer in such school related matters as fund raising events and tutoring as well. The fourth area pertains to learning at home, and here parents are involved in children's academic pursuits in home settings; for instance, helping and guiding children on how to work on home assignments given at school. The fifth area is decision making; parents are expected to work with school on issues like leadership and participation in parents' committees and dissemination of information to other parents. Collaboration with the community is yet another area of parental involvement; and this constitutes the sixth area according to Epistein 2002).

Accordingly, parents collaborate with the community in identifying resources and services from the community and consequently enhance school programmes. Therefore, parental involvement should be one of key issues for effective technology integration in the context of OST. According to Catsambis and Garland (1997), Davidson (2017), Henning (2009) and Jonston (1996), the importance of parental involvement is evident in the creation of an enabling and supportive environment that inspires OST learners to engage in learning activities. This fact is also acknowledged by some influential scholars (U.S. Department of Education, 2005; Lyness, 2014; Morin, 2018; O’ Hehir and Savelsberg, 2014).

\section{METHODOLOGY \\ Research design and Location}

The data for this paper was collected from a multiple case study which involved three regions of Tanzania, namely Arusha, Dar es Salaam and Mwanza. These regions were preferred because they represent the largest urban centres in the country while their populations were believed to be better served with technological services and devices (Lamudi, 2015; TCRA, 2013). These features and practical realities made the researcher believe that residents in the selected urban centres were more informed of educational technology and that they would be more likely to use the available technology for educational and other pursuits (Kelly, 2013). The study regions were further narrowed down such that Meru District Council (Arusha), Kinondoni Rural (Dar es Salaam) and Misungwi District Council (Mwanza) were investigated as peri-urban districts. The three districts were believed to represent moderate socio-cultural and economic features characterising majority of Tanzanians as compared to typical rural or urban settings. 


\section{The preliminary study}

The actual investigation was preceded by a preliminary study which sought to discover actual practices on how parents supported pupils who used educational technology in the home setting. It was also necessary to pick a school in which educational technology was actually used in teaching and learning, and one such a school was found in Arusha Region. The aim was to take the advantage of the respondents' experiences regarding actual use of educational technology. The researcher also though that the use of educational technology in the classroom would inspire OST learners to also use technology during OST learning; and the practice could also win the support and involvement of parents as they use educational technology during OST learning.

A sum of 22 parents of best pupils in classes 4,5 and 6 (based on previous examination results) were involved such that parents of three (3) best learners from three classes and three streams for each class were the target. As the involvement of parents was intended to identify the parental best perceived best practices of educational technology from successful stakeholders, parents of best performing pupils were the most relevant. It was rationally thought the best performing pupils would be more likely to learn before and after school and thus could also use educational technology as compared to their counterparts. Parents of class 7 learners were spared as their children had already graduated. Unstructured questionnaire was sent to parents through their children for them to indicate practices they considered the best as they guided pupils on the use of educational technology.

The perceived best practices identified by at least $50 \%$ of the respondents were incorporated in the list of the best practiced perceived by parents; and the list was verified by experts' opinions and literature review, subsequently leading to a structured questionnaire for respondents of the three research regions to rank their consensus with respect to the proposed practices. The questionnaires used the Likert scale traditions whereby respondents were to rank their perceptions in relation to each practice. In order to ensure clarity, the researcher had to familiarise pupils with the parents' questionnaires so that pupils could help parents by clarifying issues to their parents when needs arose. In case serious difficulty, parents could directly consult the researcher through the contacts given through pupils.

\section{Selection of the Research Districts and Divisions}

As explained earlier, Misungwi, Meru and Kinondoni Rural districts were involved in the study. All the administrative divisions in the districts were involved and the best school in each division was selected. As for Kinondoni Rural District, it was designed by the National Examinations Council of Tanzania (NECTA), and with the assistance of Office of the District Chief School Quality Assurance; the area was slotted into 4 approximately equal research units. This was intended to locate at most four (4) best schools in Kinondoni Rural so as to maintain a reasonable representation of the responses across the three regions.

\section{Primary schools as main participants}

The UNICEF (2011) has identified primary school pupils as among the highly vulnerable to technology abuse, given their comparatively low reasoning and cognitive abilities. Therefore, the researcher thought that the study could help to address the challenge. The selection of primary school pupils was also motivated by the need to inculcate in them positive attitudes towards the use of technology while they are still young. This could in turn inspire them to embrace educational technology as they grow. Moreover, the researcher believed that appropriate use of the research results in primary schools would help them to deal with the challenge of inadequate instructional resources.

Purposive sampling was used to select a total of 11 schools from 11 divisions in the research regions. (i.e. 1 school x 11 divisions $=11$ schools). The 2015 NECTA Primary School Leaving Examination (PSLE) results were used to select the best schools in the divisions. The purpose was to spread the selection over the districts to reflect the socio-cultural diversity of the regions. The assumption was that pupils in best schools were more likely to have engaged in OST learning more than pupils in poor schools; and thus, the probability of having engaged their parents was correspondingly higher. Similarly, parents were expected to have translated their traditional learning experiences into digital world. In total, some 78 parents filled out the questionnaire; and the Statistical Package for Social Sciences (SPSS) was deployed for data analysis.

\section{FINDINGS}

This paper attempted to explore the best practices among parents as they support primary school pupils to appropriately use the educational technology in home settings. Parents were required to indicate the degree of agreement with perceived best practices based the Likert scale with five degrees of agreement (Strongly Disagree (SD), Disagreed (D), Neutral (N), Agreed (A), and Strongly Agreed (SA)). The results are shown in the following subsections. 


\section{Buying educational technology for children's use}

The results suggest that among the best practices among parents is the tendency of parents availing pupils with educational technology. This was confirmed by the number of parents who strongly agreed with the best practice in the three research regions whereby $46.2 \%$ of them were in Mwanza, $43.5 \%$ were in Dar es Salaam and $41.2 \%$ were in Arusha. The findings showed further that none of the parents in Arusha or Dar es Salaam strongly disagreed with the practice, while also none of them in Mwanza was neutral about the practice of availing necessary educational technology to children for use during OST learning. Based on the findings, therefore, it is logical to draw the conclusion that majority of parents are ready and determined to avail educational technology to their children, suggesting that they have realised the merits associated with the use of educational technology probably in relation to improvement of academic performance of their children in school and out of school as well.

\section{Provision of guiding material on how to use the educational technology}

The questionnaire required parents to also indicate the level of their disagreement with the idea of providing guiding materials on how to use educational technology. The results unveiled that most parents were in strong agreement, as indicated by $47 \%$ of parents in Arusha, (34.6\%) in Mwanza and $43.5 \%$ in Dar es Salaam. On the other hand, some parents indicated some disagreement or neutrality about the idea. This is indicative of the predictions that the majority of parents are informed of the fact that their children can learn independently, if they have necessary materials, especially guiding materials on how to use educational technology for learning.

\section{Teaching children how to use educational technology}

As regards the need to instruct their children on the use of educational technology, between $34.6 \%$ and $39.1 \%$ of parents in the three regions were in strong agreement with the practice. Specifically, $39.1 \%$ of parents in Dar es Salaam, 35.3\% in Arusha and 34.6\% in Mwanza strongly supported the practice. Conversely, between $3.8 \%$ and $11.8 \%$ of the parents in the three study regions were strongly objected to the practice. In particular, 3.8\% of parents in Mwanza, $4.3 \%$ in Dar es Salaam and $11.8 \%$ in Arusha strongly disagreed with the practice of teaching children how to use educational technology. This implies that most of the parents found it worth teaching their children how to use the educational technologies seemingly due to the awareness that teaching children how to use technology would foster learning through technology and consequently enhance understanding of the subject matter for improved academic performance.

\section{Instruction on writing the summary of learned concepts}

With regard to the practice of giving instructions to children on how to write down the summary of the learned content as best practice, the practice generally strongly substantiated by $52.9 \%$ of parents in Arusha, $50 \%$ in Mwanza and 39.1\% in Dar es Salaam. It was also found that some parents constituting the minority of parents were opposed to the practice of instructing children on how to summarise the learned content. These included $5.9 \%$ of parents in Arusha and $4.3 \%$ in Dar es Salaam, who strongly disagreed, while none of the parents in Mwanza was neutral about instructing children on how to summarise the learned content. The findings are suggestive of the parents' commitment to instructing children on how they can write useful summaries of the content they learn and thus enhance the learning process. It could be the case that parents are informed of the advantages associated with the use of summary writing as a useful learning technique.

\section{Questioning children on learned concepts}

Among the best practices on the questionnaire was the need to find out about what children learn. Parents were thus required to state the degree of their agreement with the practice of questioning children on learned contents. The findings unveiled that the most parents strongly agreed with the practice. This is attested in $35.3 \%$ of parents in Arusha; $42 \%$ in Mwanza and $43.5 \%$ in Dar es Salaam agreed with the practice. However, the minority disagreed as shown by $5.9 \%$ of parents in Arusha who disagreed with the practice while none of parents in Mwanza or Dar es Salaam was neutral or strongly disagreed about the practice. It could be concluded then that most parents find it worth questioning children to see what they have learnt. This also suggests that parents are interested in the assessment of the degree of children's understanding of instructional contents especially those delivered through educational technology.

\section{Giving children a list of educational technology programmes}

The findings showed that between 38.5\% and $30.4 \%$ of parents were in strong agreement with idea of giving pupils a list showing all digital educational programmes available for them to use in learning out of school. In contrast, some $5.9 \%$ of parents in Arusha were opposed to the idea while $7.7 \%$ of them in Mwanza were neutral about the proposal. The situation in Dar es Salaam was different as none of the parents disagreed with the proposal. Therefore, the findings 
generally suggest that most of the parents find it useful to give pupils the lists of the programmes and encourage them to use the programme in learning especially in the OST contexts.

\section{DISCUSSION}

This paper has shown that parents are important agency for successful use of educational technology by pupils especially after school time. This observation is in line with some previous studies as expounded in the literature. For example, Scott (2013), Villarruel and Lerner (1994) and Wertsch (1991) are of the view that if the OST environment is sufficiently supervised and accompanied by relevant learning activities, educational technology can strongly enhance students' academic performance. This is also in agreement with the socio-cultural theory that calls for active engagement of parents for effective use of educational technology during OST. This suggests that parents are among the key champions of in pupils' learning especially as far as OST learning is concerned.

It has also been found that parents are also important as they ensure the availability of a variety of educational materials to reinforce the use of technologies in OST learning; and by so doing they cherish social development in children (Henderson and Berla, 1994). It has also been found that most parents buy educational technologies for their children. For instance, the Project Tomorrow (2015) unveiled that $41 \%$ of parents were willing to buy their children educational technology for use in school especially when the school so recommended. The study also discovered that $64 \%$ of the parents were willing to contribute for technology costs annually. This suggests that parents are highly committed to buy educational technology for their children and, most importantly, parents are ready to guide children on how to better exploit educational technology by supporting a variety of learning activities (Bakker and Denessen 2007).

It is important to underscore the fact that teaching children how to use the educational technology requires a lot of time such that it could prove difficult to some parents. As demonstrated by Naumanen and Tukiainen (2007), learners with less ICT experience required more time to follow instructions and eventually use educational technology appropriately. As a result, parents can use alternative mechanisms, including buying materials which can be used by children to learn to operate and use the intended educational technology. Peter (2009) is of the view that parents should also teach children the best learning practices such as summary making and asking questions to monitor learning. Pertaining to the practice of guiding children on the use of educational technology in the contexts of OST learning, studies show that the practice is positively correlated with enhanced school attendance, higher aspirations for college and positive attitudes towards school work (Clark, 1988; Hamilton and Klein, 1998; Huang et al, 2000; McLaughlin, 2000).

\section{CONCLUSIONS AND RECOMMENDATIONS}

This paper has dwelt on the perceived best practices which parents can exploit to enhance the use of educational technology among school children for learning during OST. In particular, parents can encourage pupils to use educational technology in different ways. For example, they can buy them educational technologies; provide them with guiding material on the use of technology and teaching them how to use technology. Moreover, parents could give children instructions on summary writing and ask them questions to check the understanding of the learned concepts. Finally, parents could as well supply children with a list of useful programmes to be learned through educational technology.

Based on the observed findings, it is recommended in this paper that school administration should forge partnership with parents and the community as a whole, with a view to cherishing the parental roles with respect to the use of educational technology in OST learning. Partnership is necessary as it makes a way for establishment of community centres where the community can share their resources, experiences and knowledge with regard to the use of educational technology for OST learning. Similarly, government should mount different intervention strategies that can hasten integration technology for OST learning. The strategies could include sensitization and awareness campaigns to equip parents with necessary knowledge and skills pertaining to proper use of educational technology by school children during and after school learning time. It is equally important to examine practices in schools; to this end, the government in collaboration with key stakeholders should work together and improve support towards the use of educational technology by OST learners. This partnership may constitute part of solutions to the persistent shortages of teaching and learning resources particularly in primary schools in the country. Further studies on how the schools, government and other educational stakeholders would join hand in improving the parental support towards the educational technology use by OST learners is inevitable in this $21^{\text {st }}$ technological oriented century. 


\section{REFERENCES}

1. Association for the Development of Education in Africa. (2013). African ministerial forum on ICT integration in education and training. Retrieved from https://www.adeanet.org.

2. Bakker, J. \&Denessen, E. (2007). The concept of parent involvement. Some theoretical and empirical considerations. International Journal about Parents in Education,2(2), 188-199.

3. Catsambis, S., \& Garland, J, E. (1997). Potential involvement student' education during middle school and high school. U. S Department of education: Center for Research on the Education of Students Placed at Risk (CRESPAR).

4. Clark, R. (1988), Critical Factors in Why Disadvantaged Children Succeed or Fail in School, Academy for Educational Development, New York.

5. Davis, F. (1986). A Technology acceptance model for empirically testing external factors new end user information systems: Theory and results, Cambridge, Pegaus Elliot Mackenzie Publishers Ltd.

6. Davidson, J. (2017). How to discipline a teen for getting bad grades. Retrieved from https://www.livestrong.com/article/72340discipline-teen-bad-grades/.

7. Epstein, J. (2002). School, family, and community partnerships: Preparing educators and improving schools. Boulder, CO: Westview Press.

8. Hamilton, L. \& Klein, S. (1998), Achievement Test score Gains Among Participants in the Foundation's School-age Enrichment Program, CA: Rand Corporation, Santa Monica.

9. Henning, K, J. (2009). Attitude and achievement: a study of parent and student attitudes towards education and their effects on achievement. Retrieved from https://soar.wichita.edu/bitstream/handle/10057/10 634/t13086_Henning.pdf? sequence $=1$.

10. Huang, D. et al., (2000), A Decade of Results: The Impact of LA's BEST Afterschool Enrichment Initiative on Subsequent Student 20 Achievement and Performance, University of California, California .

11. Indianapolis Afterschool Coalition (2002), "After School Programs: Basic Standards", [https://www.afterschoolcoalition.org], site visited on 23/05/2015.

12. Jonston, J. (1996). Parents facilitating educational development in the primary child: Current practice and future development. Retrieved from http://www.leeds.ac.uk/educol/documents/0000003 17.htm.

13. Kelly, A. (2013). Technology can empower children in developing countries - if it's done right. USA: Atlantic University.

14. Kiwango, T. (2006). E-commerce development and SMEs performance in Tanzania. The accountancy and business review, 3 (2),29-41.
15. Kiwango, T. (2004). ICT revolution and economic globalization: A challenge or opportunity? The accountancy and business review, 1 (2),29-32.

16. Kiwango, T. A. (2018), A model to hasten technology integration for out-of-school time primary school learning (Doctoral thesis). Tanzania: The University of Dodoma. 28

17. Lamudi, A. (2015). Which Areas Have The Best Internet Connection In Tanzania? Retrieved from https://www.lamudi.co.tz/journal/which-areashave-the-best-internet-connection-in Tanzania.

18. Lyness, D. (2014). 10 Ways to help your children succeed in elementary school. Retrieved from https://kidshealth.org/en/parents/school-helpelementary.html

19. McLaughlin, M. (2000), Community Counts: How Youth Organizations Matter for Youth Development, Public Education Network, Washington, $D C$

20. NECTA. (2014). PSLE-2014 Examination results. Retrieved from https://necta.go.tz/psle2014/results/distr_0105.htm.

21. Naumanen, N. \&Tukiainen M. (2007). Taught and learnt international conference on cognition and exploratory learning in digital generation. Retrieved from https://www.cs.joensuu.fi/pages/int/pub/naumanen0 7b.pdf.

22. Peter, P. (2009). How to teach summarizing: A critical learning skill for students. Retrieved from https://peterpappas.com/2009/11/how-teachsummarizing-essential-critical-learning-skillstudents.html.

23. Project Tomorrow. (2015). What do parents really think about digital learning? Retrieved from https://www.tomorrow.org/speakup/speakup-201510-things-parents-think-about-digitallearning.html.

24. Rogers, E. (2003), Diffusion of Innovations (5th ed.). The Free Press, New York.

25. Scott, S. (2013). Sociocultural theory. Retrieved from

https://www.education.com/reference/article/socioc ultural-theory/.

26. TCRA (2013). “Assessment Report on Migration from Analogue to Digital Broadcasting and Analogue Switch-off Processes in Tanzania. Retrieved from http://www.tcra.go.tz/index.php/publication-andstatistics/reports.

27. Terzian, M., Giesen. L., \&Mbwana, K. (2009). Why teens are not involved in out-of-school programs, the youth perspectives. Retrieved from https://www.childtrends.org/wpcontent/uploads/2013/04/6.pdf.

28. UNICEF. (2011). Cities and Children: The Challenge of Urbanization in Tanzania. Retrieved from

https://www.childwatch.uio.no/news/2012/citiesand-children_tanzania.pdf 
29. U.S. Department of Education (2005). Helping Your Child Succeed in School. Washington, DC.

30. Villarruel, F. \& Lerner, R. (1994). Development and Context and the Contexts of Learning. San Francisco, Jossey-Bass.

31. Wertsch, J. (1991). Voices of the mind: A SocioCultural Approach to Mediated Action. UK, Harvard University Press.

32. WSIS. (2003). Basic information about WSIS. Retrieved from https://www.itu.int/wsis/basic/about.html.

33. Zedan, R., F. (2011). Parental involvement according to education level, socio-economic situation, and number of family members. Journal of educational enquiry, 11(1), 13-28. 